sonableness thereof, both as to space desired and equipment asked for. It is then his duty and province to evaluate their demands and bring them into proper relation with the whole on the basis of modern medical knowledge and principles and methods of administration.

University Hospital.

\section{THE TONSILS AS A HABITAT OF ORAL ENDAMEBAS}

POSSIBILITY OF SYSTEMIC COMPLICATIONS OF ORAL, ENDAMEBIASIS *

ALLEN J. SMITH, M.D. PHILADELPHIA

WILLIAM S. MIDDLETON, M.D. MADISON, WIS. AND

\section{T. BARRETT, D.D.S.} PHILADELPHIA

In connection with work recently carried on by Smith and Barrett in the pathologic laboratories of the University of Pennsylvania ${ }^{1}$ indicating that the parasitic amebas of the mouth hold an important relation in the etiology of pyorrhea alveolaris or Riggs' disease, and that by the use of emetin (alkaloid) as an amebicide these organisms may be destroyed and the pyorrheal lesions cured, we have sought to determine whether these protozoa may not find their way also into the tonsils and there perhaps be of importance in determining or in maintaining certain of the inflammatory lesions of these structures, at least with or without associated systemic complications. To the present time only the first of these propositions can be said to be proved, that is, that these parasites actually at times involve the tonsils. The conditions of the tonsils of persons in whom they have been found infested, and the behavior of several positive cases with systemic complications after the administration of emetin; however, are decidedly suggestive and encouraging to continued investigation now in hand.

In the work of Smith and Barrett the endamebas encountered in pyorrhea pockets have almost invariably been of the species Endamoeba buccalis Prowazek, 1904 (probably identical with Endamoeba gingia'alis Gros, 1849 and Endamoeba buccalis Steinberg, 1869); two of their cases to date being regarded by them as Endamoeba kartulisi Döflein, 1901. They are uncertain, but regard it not improbable that of the instances held primarily as Endamocba buccalis, certain ones may represent a third, as yet unclassified species. These organisms have been long known, but have been hitherto uniformly held to be non-pathogenic parasites of the mouth, on the supposition that they do not penetrate the tissues, are merely surface habitants, and are found in normal as well as in pyorrheic mouths. Barrett in his report of their work records the uniform discovery of endamebas in the pus of pyorrhea pockets in forty-six patients, without exception; offers as controls seven mouths free (after careful dental examination) from pyorrhea, and free also of amebas; and records to the date of

* From the Pathological Laboratories of the School of Medicine, University of Perinsylvania, and the Department of Clinical Medicine, Iniversity of Wisconsin.

1. For freliminary report, see Barrett: Dental Cosmos, August, 1914 his report before the Pennsylvania Dental Society (July 1, 1914) thirteen cases of Riggs' disease treated with emetin either with complete cure or with marked progress toward recovery. Since then all of these patients have fully recovered and numerous additional cases have been collected showing the presence of endamebas in pyorrhea pockets and the effectiveness of emetin in their destruction and in the cure of the suppuration.

In the latter part of July, 1914, before the American Dental Society of Europe, in session at the time in Paris, Dr. Angelo Chiavero, ${ }^{2}$ a dentist of Rome, in a paper devoted to the morphologic and systematic study of Endamoeba buccalis, records his invariable discovery of the parasites in twenty-two cases of alveolar pyorrhea, its fiequent presence in the soft deposits on sound teeth not kept in good hygienic condition, its absence from carious dental cavities in active process of decay and its absence from hard tartar. In his conclusions, however, he states his belief that these organisms are of no pathogenic influence, but that $\mathrm{te}$ regards them, from the fact that they feed on basteria, as adjuvants to autodisinfection of the mouth.

Still more recently Bass and Johns ${ }^{3}$ of $\mathrm{New}$ Orleans have announced their discovery of these endamebas in eighty-five out of eighty-seven cases 'diagnosed as Riggs' disease which they have had the opportunity of examining, and declare the curative efficiency of emetin administered hypodermatically. The results which have been obtained from the use of emetin, whether employed locally or administered hypodermatically, constitute an appealing argument for the actual pathogenic importance of these protozoa, an argument short only of ideal proof by successful inoculation of pure cultures ${ }^{4}$ and surely of equal significance to the old "therapeutic tests" with mercury and iodids for syphilis and with quinin for malaria.

When one realizes the readiness with which along with the purulent discharge these parasites may emerge from the pyorrhea pockets, and the favorable circumstances for their active and passive distribution over the surface of the oral mucous membrane and of the teeth, thefe is little reason for wonder and no strong force of argument in the fact that they are found on these surfaces. There is as little reason to hold the frequency of their occurrence as human parasites as an objection to their pathogenicity if one remembers that it is commonly held by the dental profession that pyorrhea alveolaris is, with the exception of dental caries, the most frequent disease which affects humanity and that with careful examination by competent dentists an overwhelming proportion of all persons applying for all sorts of dental affections are found to have in obvious or in less degree some suppurative peridental lesions. Even if trivial, these may be the habitat of amebas and the source of those found on the free surfaces. It would be as reasonable to contend that because the endamebas of dysentery are found in the dejecta they do not also penetrate the tissue of the colonic wall. The pyorrhea pockets may very properly be held the analogs of the ulcerous excavations found in the

\footnotetext{
2. Chiavero, Angelo: Abstr., Dental Cosmos, September, 1914.

3. Bass and Johns: New Orleans Med. and Surg. Jour., 1914, 1xvii,

4. Smith and Barrett (personal communication) have succeeded in obtaining indifferent and always bacterially contaminated cultures on fresh egg albumin, but have not succeeded in isolating tie amebas so as to nake inoculation experiments practicable.
} 
mucosa and submucosa of the colon in amebic dysentery; and, while it is equally true of both locations that the endamebas which are actually at a given moment on the surface of the mucous membranes are not at that particular time causing disease, each species in its place by penetrating into the tissue produces a suppurating excavation, a "pocket" or an ulcer. The precise rôle in each instance of associated bacteria cannot be asserted; but there is reason to suspect their conjoined importance and, too, an important symbiotic relation between the protozoa and the bacteria.

Believing that from their proximity to pyorrhea pockets and their favoring anatomic structure the tonsils might be invaded and form another habitat for these endamebas, we made a number of examinations of tonsils to determine their occurrence in these organs. In examining the tonsils for parasitic amebas, because of the difficulty occasioned by want of technical skill in obtaining from these organs a proper amount of material for examination, the search was restricted at first to freshly excised tonsils, the examination being made directly in the operating room as quickly as the tonsils were removed. All the tonsils thus examined were removed by Dr. Ralph Butler of Philadelphia, to whom we wish to express our feelings of indebtedness. The excised tonsil was squeezed to discharge the more superficial contents of the crypts; and after this had been removed, by firmer pressure the deeper contents of the crypts and perhaps some of the interstitial juices were forced to the surface and examined on a warm slide, diffused in a small drop of warmed normal saline solution. Seventeen cases were thus examined, five of the number showing motile amebas of the type of Endamocba buccalis Prowazek, and regarded by us as this organism. In the material obtained from a sixth case an ameboid type of cell, with multiple long slender almost filiform pseudopodia composed of clear material, and with a granular body roughly measuring 20 micromillimeters in diameter, non-vacuolated and with a small and clearly visible body regarded as the nucleus, was found. It was not unlike Amoeba gracilis (a form once encountered by one of us in a subphrenic abscess). No motility could be determined, however, and while it is believed to have been an ameba, uncertainty is acknowledged and the case is not included in the list of positive tonsillar infestations. All of these seventeen cases were instances of some type of chronic tonsillitis, usually with tonsillar hypertrophy. The tonsils of the five persons in whom these organisms were demonstrated were all large, with pouting crypts; and were removed from young persons presenting the usual local and general symptoms of chronic tonsillitis with irregularly occurring exacerbations. The cases were not followed up beyond the point of determination of the parasitism, since, at the time, the establishment of this as a fact was the prime purpose in hand.

During the same time attempts were made, but in no instance with success, to obtain material from the tonsils in situ by scraping out the contents of enlarged crypts with a suitable pointed instrument. Later, however, with a fine pointed glass pipet to which was attached a strong suction bulb it was found comparatively easy to withdraw a small amount of semifluid material from the depths of the crypts, sufficient for microscopic examination. The tonsils are practically insensitive to the operation, and the point of the pipet may be introduced without discomfort into the crypts to such a depth that when suction is applied numerous red blood-cells are withdrawn in the viscid fluid which enters the lumen of the tube, indicating that more than mere cryptal contents are obtained. This is placed, with or without dilution, in warmed normal saline solution, on a warmed slide, covered, and examined without further preparation for the moving amebas. Permanent preparations may of course be made by fixing the film, preferably in warm Schaudinn solution, and staining with Giemsa's stain or with iron hematoxylin; but for diagnostic purposes the recognition of the moving parasites is advantageous and satisfying. We have thus far not found the organisms in this tonsillar material in numbers comparable to those ordinarily noted in the material from pyorrhea pockets, but believe that with better methods of withdrawal of material they will be found more frequently and in larger numbers.

Riggs' disease has for years been suspected of primary relationship to various systemic disturbances, including particularly certain .chronic or recurrent arthritic affections, and possibly, too, some of the anemias of obscure origin and degenerative lesions of various parenchymatous organs; and even greater suspicion, amounting almost to certainty, has attached to tonsillar affections in relation to such systemic complications. Following these ideas, which are essentially those of Hunter ${ }^{5}$ and others, the possibility of more generalized influences must necessarily occur, the effects of either the endamebiasis or of the associated bacteria, or both. Direct extension of the inflammatory processes, or lesions due to metastasis by lymphatic or hemic convection, or due to the effects of swallowed or absorbed toxic products are, logically, at least to be thought of.

In several instances in the series of cases treated for pyorrhea by Dr. Barrett, there has been noted, after the cure of the pyorrhea, the disappearance of symptoms of gastric and intestinal disorders. Similar experience has been related to us by several dentists following emetin medication; and while perhaps in a few cases this may be due to the happy effect of a coincidence of pyorrhea and amebic dysentery (as in a case communicated by Dr. F. C. Narr of Philadelphia to us), this explanation can be accepted only in exceptional instances. It would rather sug. gest that the cure of the oral lesions has diminished the bacterial and other poisons which previously had been swallowed and had been causative of some grade of gastritis.

During the latter part of the summer in the wards of Dr. B. F. Stahl in the Philadelphia General Hospital six cases of chronic arthritis were examined, in four of which endamebas were discovered in material thus obtained from the tonsils. These were all adults.

CASE 1.-A white male patient had been recently admitted with a history of arthritis of ten months' duration, in one knee, an ankle and both shoulders. The tonsils were not especially enlarged, but showed prominent crypts with the tissue immediately surrounding them turgid, boggy and red, giving the crypts a pouting appearance. There was a history of recurrent, mild, apparently causeless sore throat. Under treatment with salicylates the conditions in the tonsils and joints cleared fairly promptly; and two examinations thereafter failed to show the presence of endamebas, which at first were readily encountered along with numerous spirochetes and bacteria.

5. Hutter: Brit. Med. Jour., Nov. 19, 1904. 
CASE 2.-The patient, a white man, was admitted with a subacute arthritis of supposed Neisserian origin, affecting the right ankle. The tonsils were of the same type as in the preceding case, and material removed by pipettage showed occasional amebas. The case cleared up symptomatically on ordinary treatment in about four days, succeeding which period three examinations on different days failed to show the persistence of any endamebas.

CASES 3 and 4.-Both patients were afflicted with chronic arthritis, but presented no appreciable tonsillar lesions. Material taken by pipettage from the retrotonsillar space in front of the faucial pillars revealed no endamebas in either. (We regret that tonsillar puncture was not performed for obtaining material, as we believe that the proper material, suggested by the blood-cells always obtained in the pipet, is really not merely of cryptal but also of interstitial source.)

CASE 5.-A white woman, with typical rheumatoid arthritis, with the small joints of the hands and feet, the joints of the jaw, elbows, ankles and knees and of the spinal column affected, gave a history of recurrent sore throat. Her tonsils were fibroid; the tonsillar tissue on the right side just anterior to the posterior pillar red and beefy in appearance. Amebas have been found repeatedly from material from the latter situation.

CASE 6.-A white man with chronic arthritis (involving both knees, ankles, wrists and elbows, and the small joints of the hands and feet) had cryptal enlargement in both tonsils, with a deep red boggy appearance of the pericryptal tissue of the tonsils, this more marked on the left than on the right side. Amebas were readily found in the material with-

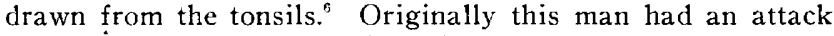
of acute articular rheumatism eighteen or twenty years ago, with persistence of subacute symptoms for six months afterward. In the interim, while suffering from occasional twinges of pain in various joints (never disabling) he was free from acute symptoms until four months prior to his present admission to the hospital; and at irregular periods had a recurrent sore throat usually without appreciable cause. In the spring of the current year he developed a septic thrombophlebitis of the right internal saphenous vein for which he was treated in the Philadelphia Hospital, being kept in bed almost continuously for six or eight weeks. He was thereafter discharged from the hospital; but until his readmission about eight weeks later he was never free from pains in his joints, although able to move about without much difficulty, but with many of his joints showing permanent enlargement. He was readmitted to the hospital in a state of intoxication and was assigned to the "drunk ward," where he soon developed an acute exacerbation with arthritic involvement as stated above, and with moderate swelling and redness evident about many of the involved joints. For a week he was actively treated with sodium salicylate and bromid of sodium, but without appreciable effect on the arthritic condition. At this time endamebas were found in the tonsils (and too in pyorrhea pockets); and from August 6 the patient was given thrice daily 1/4, grain of emetin hydrochlorid (by mistake by the mouth, although ordered hypodermatically). August 9 he was entirely free from pain in the joints and from the redness and swelling except in the knees. From the last date he was given $1 / 3$ grain of emetin daily hypodermically, and on August 12 he was free from all acute arthritic symptoms, but with persisting enlargement of the joints. Thus improved he was discharged.

CASE 7.-A somewhat similar case was communicated to us by Dr. Gibson Smith of the intern staff of the Murray Hospital of Butte, Mont. The subject, a white adult, a miner, had had subacute arthritic symptoms involving the joints of the neck, elbows, wrists, fingers, knees, ankles and toes for five or six months continuously, with irregular exacerbations through this period. He had had his upper teeth removed fifteen years before, presumably because of pyorrhea, and has

6. The rapid hemolysis of a freshly englobed red blood-cell in one of these endamebas is noted in this case, and is of interest; disappearing without fragmentation by solution in the course of five minutes. The same phenomenon had pyorrhea about the lower teeth at least ever since. Numerous motile endamebas were found by Dr. Smith in pus from the pyorrhea pockets. No examination of material from the tonsils was made, these organs appearing normal grossly. The pyorrhea was treated locally with emetin hydrochlorid, and in addition the drug was administered hypodermatically. Within four days the gingival suppuration had ceased and the amebas could no longer be found in scrapings from the pockets; the joint symptoms had subsided and the patient was able to return to his employment for which he had previously been incapacitated more or less of the time. No report has been received to indicate whether or not the improvement has continued.

Two other cases, one referred through the kindness of Drs. Krumbhaar and Gerhard from the medical dispensary of the Pennsylvania Hospital, the other a patient in the medical ward of the University Hospital examined by permission of Dr. Stengel, have been found to have amebic oral infestation.

CASE 8.-The first of these, A. A., a white woman, aged about 40 or 45 , was regarded by the dispensary physicians as having chronic toxic arthritis, and had been referred to the throat dispensary of the hospital, where it was advised that removal of one of the tonsils be performed because of a diffuse interstitial tonsillitis. Endamebas were found in pyorrhea pockets about several of her teeth, and in the affected tonsil. Emetin treatment was suggested for trial; but difficulty in obtaining the drug for use in the dispensary postponed for several weeks its employment, and no report has thus far been afforded.

CASE 9.-The second case, that of A. R., a white woman in Dr. Alfred Stengel's wards in the University Hospital, presented the usual features of long-standing arthritis deformans. She was found to have a marked case of pyorrhea with endamebas in the pockets; but no parasites were found in the tonsils. Emetin was to have been used in the case, but on trial caused an unpleasant nausea and it was at once suspended.

In the original series of cases reported by Dr. Barrett as treated by local administration of emetin hydrochlorid for pyorrhea there was a young white woman with a marked but unstudied anemia, poorly nourished and in a depressed condition of general health. Since her recovery from the pyorrhea, a matter of about three months, she has acquired an excellent color, has added 15 pounds in weight and is now in excellent general condition. This case suggested the possibility that some of the obscure anemias, especially those suspected of being of hemolytic origin, might find their explanation in oral endamebiasis. Thus far we have had the opportunity of examining the mouths in three cases regarded as pernicious anemia and in all three have found Endamoeba buccalis in the gums and in one of the three also in the tonsils. All three of these patients have been receiving treatment with other remedies, and it is quiie impossible to know whether the emetin applied locally and hypodermatically to two of them has had any influence or not. One of the two, improving under sodium cacodylate and iron, has improved continuously and apparently especially after local treatment of his pyorrhea and hypodermic administration of emetin hydrochlorid. A less marked but distinct temporary improvement was noted in the second, although at present the blood-picture has receded; here, too, the emetin was only incidental to treatment with sodium cacodylate and iron citrate.

7. Reported Oct. 15, 1914, that after recurrence of arthritis with well-narked redness and swelling on September 16, an intramuscuiar injection of 2 grains of emetin hydrochlorid was promptly followe by disappearance of all arthritis symptoms, without any return to da:e of rewort. 
We freely acknowledge that the scant data here presented can in no wise be interpreted as proving that oral endamebiasis is surely a factor of generalized intoxication in the production of arthritis or anemia. We believe, however, that the positive finding of the parasitism in connection with these conditions and the favorable features mentioned as met after administration of emetin in these few isolated cases are sufficiently suggestive to warrant further trial. In study of the possible relation it would be illogical to suppose that the toxic states determining either the arthritides or the anemias must either entirely or always be due to the oral condition; at best, if there be a relation, that ean be true only in individual cases. Efforts to determine a relationship are sure to fail frequently, and failures are bound to be recorded (even if we are correct in our suspicions) until sufficient knowledge and experience are had to select properly, directly or by elimination, the appropriate cases. It is illogical to even suspect that, granted the existence in an individual of oral endamebiasis, there must necessarily be systemic complications, or that such complications must be of uniform character. Much must depend on the local circumstances governing absorption, and much, too, must depend on the number and type of associated bacteria. Whatever other relation may obtain between the amebas and the accompanying vegetable micro-organisms, one may be certain that the amebas feed largely "on the latter; and in this bacterial phagocytic action they doubtless set free from this and from that organism different endotoxins. Doubtless bacterial toxins thus originating play a more important part than do toxins from the amebas themselves, if there be amebic toxins; and the end-results of toxic absorption are sure therefore to vary, now manifesting as hemolysis, now as cellular degenerations or necroses of fixed tissues, now as inflammatory changes as of synovial or serous membranes.

\section{CROTALIN IN EPILEPSY*}

C. L. JENKINS, M.D., AND A. S. PENDLETON, M.D. First Assistant Pinysician and Clinical Pathologist; Respectively, State Hospital

RALEIGH, N. C.

On account of the wide publicity given through the lay press to the supposedly wonderful results to be obtained from the use of crotalin in the treatment of epilepsy, we feel that we owe it to the profession to present to it the results obtainêd from this treatment at the Epileptic Colony at the State Hospital at Dix Hill.

First, we wish to state that this treatment has. been given under and by the direct advice of Dr. Thomas J. Mays, one of its chief advocates, and to say further that his instructions have been faithfully carried out.

The advocates state that the principle on which this treatment depends is the fact that crotalin decreases the coagulability of the blood, and they assert that the coagulability is increased in epilepsy. We wished to confirm or refute this and very readily did so by making use of a Boggs coagulometer, which was first carcfully tested out on normal blood at a temperature of from 60 to $65 \mathrm{~F}$., the temperature at which the abnormal blood was tested. The mean coagulation time for this particular instrument was $66 / 17$ minutes. The mean coagulation time for the blood of

* Read before the North Carolina Medical Society. nine epileptics who had received no croialin was $127 / 9$ minutes. The mean coagulation time for the blood of eleven epileptics who had received about forty doses of the remedy was $93 / 11$ minutes, while the mean coagulation time of the blood of thirteen epileptics who had been given eighty or more doses was $74 / 13$ minutes. These findings would indicate that the exact opposite to the assertions of the advocates is true, and this is further in accord with the well-known serologic principle that the injection of any foreign substance into the blood causes the formation of antibodies.

That this condition of the blood is exceedingly transitory seems probable, as in three patients who had taken no crotalin in three weeks (though they had previously received over one hundred doses) the mean coagulation time was $141 / 3$ minutes.

In a more recent paper, Dr. Mays states that he uses crotalin on account of its pharmacologic effect, saying that its action is very similar to that of the cyanids. Let us hope that he is nearer right in this than in his former contention. We are afraid, however, that even this is not entirely true, as practically all of the patients assert that they get decided stimulation from the therapeutic dose of this drug, and the cyanids have never been accused of any such action.

CONVULSIONS DURING TIME OF OBSERVATION

\begin{tabular}{|c|c|c|c|c|c|c|}
\hline \multirow{2}{*}{$\begin{array}{l}\text { Period } \\
\text { hree months } \\
\text { before treat- } \\
\text { ment }\end{array}$} & \multirow{2}{*}{$\begin{array}{c}\text { Dosage } \\
\text { No crotalin }\end{array}$} & \multirow{2}{*}{$\begin{array}{l}\text { Time. } \\
\text { January } \ldots \\
\text { February } \ldots \\
\text { March } \ldots\end{array}$} & \multicolumn{4}{|c|}{$\begin{array}{l}\text {-Number of Convulsions- } \\
\text { Men Women Tot. Gr. Tot. }\end{array}$} \\
\hline & & & $\begin{array}{l}215 \\
241 \\
280\end{array}$ & $\begin{array}{l}135 \\
190 \\
214\end{array}$ & $\begin{array}{l}350 \\
431 \\
494\end{array}$ & 1,275 \\
\hline $\begin{array}{l}\text { First th ree } \\
\text { months of } \\
\text { treatment }\end{array}$ & $\begin{array}{l}10 \mathrm{~min} \mathrm{ims} \\
\text { twice a week }\end{array}$ & $\begin{array}{l}\text { April } \ldots . \\
\text { May } \ldots \ldots \\
\text { June } \ldots . .\end{array}$ & $\begin{array}{l}277 \\
333 \\
231\end{array}$ & $\begin{array}{l}267 \\
286 \\
246\end{array}$ & $\begin{array}{l}544 \\
619 \\
477\end{array}$ & 1,640 \\
\hline $\begin{array}{l}\text { Second three } \\
\text { months of } \\
\text { treatment }\end{array}$ & $\begin{array}{l}10 \mathrm{~min} \mathrm{ims} \\
\text { once a week }\end{array}$ & $\begin{array}{l}\text { July } \ldots . \cdots \\
\text { August } \ldots \ldots \\
\text { Sejémber }\end{array}$ & $\begin{array}{l}263 \\
209 \\
244\end{array}$ & $\begin{array}{l}282 \\
289 \\
260\end{array}$ & $\begin{array}{l}545 \\
498 \\
504\end{array}$ & 1,547 \\
\hline $\begin{array}{l}\text { Third th } \mathrm{rce} \\
\text { months of } \\
\text { treatment }\end{array}$ & $\begin{array}{l}5 \text { minims once } \\
\text { a week }\end{array}$ & $\begin{array}{l}\text { Octolier } . . \\
\text { November } \\
\text { Deccmber }\end{array}$ & $\begin{array}{l}253 \\
250 \\
255\end{array}$ & $\begin{array}{l}235 \\
233 \\
247\end{array}$ & $\begin{array}{l}488 \\
483 \\
522\end{array}$ & 1,493 \\
\hline $\begin{array}{r}\text { Three months' } \\
\text { trea t m e } 12 \mathrm{t} \\
\text { discontinued }\end{array}$ & & $\begin{array}{l}\text { March } \ldots \\
\text { April } \ldots \\
\text { May } \ldots .\end{array}$ & $\begin{array}{l}157 \\
274 \\
257\end{array}$ & $\begin{array}{l}201 \\
250 \\
222\end{array}$ & $\begin{array}{l}358 \\
524 \\
479\end{array}$ & 1,3 \\
\hline
\end{tabular}

In poisonous doses it does cause convulsions-whether or not for the same reasons that the cyarids doremains to be proved. He tells us that the homeopaths have been using snake-venom by mouth for many years for epilepsy and by inference we are led to suppose that he has been converted to "the hair of the dog is good for the bite" theory. In this dissertation he further attempts to explain the nature of epilepsy, with the usual result.

Differential blood counts in nineteen patients who had received from forty to one hundred closes showed a tendency to slight eosinophilia with a slight increase in mononuclears, with no apparent effect on the total number of leukocytes or on the red blood cells, nor did the hemoglobin seem to be affected. In two cases with abscesses the septic factor was present, as would be expected.

The drug is supplied in solution, 5 minims of which equals $1 / 100$ grain, and the directions are to give it hypodermatically twice a week, beginning with 4 minims and increasing to 10 . Later advices were to give no more than 5 minims. The hygienic and dietetic treatment was the same for these as for other patients.

To determine its effects on the number of convulsions, it was decided to record accurately every con- 